\title{
The Effects of Diverticulum Localization and Hinchey Classification on Recurrence and Complications in Acute Colonic Diverticulitis
}

\author{
Mahmut Kaan Demircioglu, (1) Zeynep Gul Demircioglu, (i) Mustafa Fevzi Celayir, (ㄷ) Cemal Kaya, \\ Mehmet Mihmanli
}

Department of General Surgery, University of Health Sciences Turkey, Sisli Hamidiye Etfal Teaching and Research Hospital, Istanbul, Turkey

\begin{abstract}
Objectives: Diverticular disease of the colon is a pathology that arises from outward ballooning of the mucosa due to some weakness in the muscle layer. Diverticular disease may range from symptomatic uncomplicated diverticular disease to symptomatic disease with complications, such as acute diverticulitis or diverticular bleeding. Acute colonic diverticulitis occurs in about $10-25 \%$ of patients. Methods: In this study, 134 patients who were admitted to our emergency clinic with complaints of abdominal pain between 2016-2019 and hospitalized with the diagnosis of acute diverticulitis were included. Patients' sex, age, presence of additional disease, increase in leukocyte and C-reactive protein (CRP), localization of diverticulitis, Hinchey classification, mean length of hospital stay and treatment were evaluated. The effects of these parameters on complications and recurrence were statistically analyzed. Results: The length of hospital stay was statistically significantly associated positively with the Hinchey classification ( $p<0.001)$. While 18 patients who were medically treated developed recurrence later, and this rate was statistically significant ( $p<0.001)$. When one of the factors, localization, which may play a role in the severity of the disease and recurrence are examined, was evaluated concerning its results in our study, we found that rectosigmoid location is an important factor for recurrence. We found that the localization in the colon and the severity of the disease were effective in the prognosis of acute diverticulitis.

Conclusion: We believe that localization and the severity of the disease should be taken into consideration when planning surgery in these patients.

Keywords: Acute diverticulitis; complication; diverticular disease; recurrence.

Please cite this article as "Demircioglu MK, Demircioglu ZG, Celayir MF, Kaya C, Mihmanli M. The Effects of Diverticulum Localization and Hinchey Classification on Recurrence and Complications in Acute Colonic Diverticulitis. Med Bull Sisli Etfal Hosp 2020;54(4):451-456". iverticular disease of the colon is a pathology that arises from outward ballooning of the mucosa due to some weakness in the muscle layer. ${ }^{[1]}$ Especially in industrialized western countries, it is seen increasingly with the increase in the elderly patient population and with the discovery of new diagnostic methods. Although this disease is more common in the right colon in eastern societies, it

is generally located in the left colon in western societies. ${ }^{[2]}$ Its prevalence is below $10 \%$ in people under 40 years of age and up to $65 \%$ in patients over 80 years of age. ${ }^{[3]}$

Diverticular disease may range from symptomatic uncomplicated diverticular disease to symptomatic disease with complications, such as acute diverticulitis or diverticular bleeding.
\end{abstract}

$\mathrm{D}$

Address for correspondence: Mahmut Kaan Demircioglu, MD. Saglik Bilimleri Universitesi, Sisli Hamidiye Etfal Egitim ve Arastirma Hastanesi, Genel Cerrahi Klinigi, Istanbul, Turkey

Phone: +90 5373896203 E-mail: mahmutkaandemircioglu@gmail.com

Submitted Date: August 19, 2020 Accepted Date: October 16, 2020 Available Online Date: December 11, 2020

${ }^{\circ}$ Copyright 2020 by The Medical Bulletin of Sisli Etfal Hospital - Available online at www.sislietfaltip.org

OPEN ACCESS This is an open access article under the CC BY-NC license (http://creativecommons.org/licenses/by-nc/4.0/). 
Acute colonic diverticulitis is seen in approximately $10-25 \%$ of patients. ${ }^{[4]}$ While most of these patients are treated medically, most of the patients who develop complications, such as perforation, peritonitis and bleeding, are hospitalized. However, emergency surgery is required in $25 \%$ of patients upon the development of perforation, peritonitis or systemic complications. ${ }^{[4]}$ Hinchey classification is generally used to determine patients' follow-up and treatment.

This classification is a highly sensitive radiological assessment using abdominal computed tomography (CT). ${ }^{[5]}$ In our study, we aimed to evaluate the effects of the localization of diverticulum and Hinchey classification on complications and recurrence in acute diverticulitis.

\section{Methods}

For our study, research permission was obtained from the local ethics committee on 11.02.2020, numbered 2675.

In this study, 134 patients who were admitted to our emergency clinic with complaints of abdominal pain between 2016-2019 and hospitalized with the diagnosis of acute diverticulitis were included. All patients underwent oralintravenous (IV) contrast abdominal CT, as well as their biochemical parameters, were obtained. Patients with uncomplicated diverticulitis were administered IV antibiotherapy with a clear liquid diet until symptoms subsided, and in more severe cases, oral intake was discontinued and parenteral support therapy and IV antibiotics were administered. IV antibiotics were chosen in the same procedure: Metronidazole $1.5 \mathrm{gr} /$ day and 3rd generation cephalosporin (cefotaxime) $3 \mathrm{gr} /$ day. Oral Metronidazole $1.5 \mathrm{gr} /$ day plus Ciprofloxacin $1 \mathrm{gr} /$ day was administered to the patients after discharge for seven days. Surgical treatment was performed in patients with acute abdominal findings. Elective surgery was performed for eight patients with coloenteric fistula, colocutaneous fistula and colovesical fistula. According to the American Society of Colon and Rectal Surgeons (ASCRS) 2020 guideline, we performed elective colon resections for uncomplicated seven patients after second relapse. Colonoscopic control was performed on all patients who had no surgical resection 4 to 8 weeks after the acute findings were resolved. Patients with a history of diverticulitis and who were detected to have a malignancy or inflammatory bowel disease after colonoscopy were excluded from this study. Patients' sex, age, presence of additional disease, increase in leukocyte and C-reactive protein (CRP), localization of diverticulitis, Hinchey classification, mean length of hospital stay and treatment were evaluated. The effects of these parameters on complication and recurrence were statistically analyzed.

\section{Statistical Analysis}

SPSS 15.0 for Windows (SPSS Inc, Chicago, IL, USA) program was used for statistical analysis. Descriptive statistics; number and percentage for categorical variables, mean, standard deviation, minimum, maximum for numerical variables were used. When the numerical variables met the normal distribution condition, the comparisons of two independent groups were performed using Student's t-test and Mann-Whitney $U$ test when they did not meet the normal distribution condition. In more than two groups, numerical variables were analyzed using the Kruskal Wallis test because they did not meet the normal distribution condition. Subgroup analyzes were performed using the Mann-Whitney $U$ test. The ratios in the groups were compared with the Chi-Square Analysis. Relationships between numerical variables were analyzed using Spearman Correlation Analysis since parametric test conditions were not met. Statistical significance level of alpha was accepted as $p<0.05$.

\section{Results}

The mean age of 134 patients who were treated for acute diverticulitis in an average of three years was $57.7 \pm 15.3$ years; $47.8 \%$ of the cases were male, and $52.2 \%$ were female.

Diverticula were the most common in the sigmoid colon (63.2\%), descending colon (19.5\%) and cecum (14.3\%) in terms of localization. The majority of diverticulitis (82.2\%) was evaluated as stage 1 according to the Hinchey classification following abdominal CT of patients. The vast majority of patients $(83.6 \%)$ responded to medical treatment. The mean length of hospital stay was $4.6 \pm 3.8$ days, with a mean follow-up time of 38 months (8-46 months). During treatment and follow-up, complications were observed in $17.2 \%$ of patients and recurrence in $18.7 \%$.

Eleven of the complications were perforation, four were abscess, three were stenosis and three were bleeding. While $83.6 \%(n=112)$ of the patients were treated medically, $11.9 \%(n=16)$ had emergency surgery, $3 \%(n=4)$ had elective surgery and $1.5 \%(n=2)$ had percutaneous drainage.

Hartmann's resection was performed in nine patients, resection and protective ileostomy in eight patients, and resection and anastomosis in three patients. One patient died due to multiorgan failure following sepsis during the treatment of acute diverticulitis. No relationship was detected between complication rate and sex and age in patients.

The length of hospital stay was statistically significantly correlated with the Hinchey classification $(p<0.001)$. The 
mean length of hospital stay of patients with Hinchey classification Stage 1 was statistically significantly lower than those with Hinchey Stage 2 and above $(p<0.001)$. The mean length of hospital stay of patients undergoing emergency surgery was statistically significantly higher than those who received medical treatment $(p<0.001)$. Patients who had complications had higher Hinchey stage and surgical intervention rates. There was no relationship between the complication rate and localization of diverticulum. The mean duration of hospital stay and recurrence rate of patients with complications were statistically significantly higher than those without compli- cations $(p<0.001, p=0.040)$.

No relationship was found between the recurrence and age and sex of the patient. The localization of the disease was the rectosigmoid region in the majority of patients with recurrence, and this rate was significantly lower in those with cecum localization ( $p=0.012, p=0.023$ ).

According to the Hinchey classification, there was no significant relationship between the stages in terms of recurrence (Table 1). Recurrence occurred in 18 of the medically treated patients, while this rate was found statistically significant $(p<0.001)$.

Table 1. Recurrence rates and patient characteristics

\begin{tabular}{|c|c|c|c|c|c|}
\hline & \multicolumn{4}{|c|}{ Recurrence } & \multirow[b]{3}{*}{$\mathbf{p}$} \\
\hline & \multicolumn{2}{|c|}{ Absent } & \multicolumn{2}{|c|}{ Present } & \\
\hline & $\mathbf{n}$ & $\%$ & $\mathbf{n}$ & $\%$ & \\
\hline \multicolumn{6}{|l|}{ Sex } \\
\hline Male & 53 & 48.6 & 11 & 44.0 & 0.676 \\
\hline Female & 56 & 51.4 & 14 & 56.0 & \\
\hline Age Mean $\pm S D$ (Min-Max/Median) & \multicolumn{2}{|c|}{$58.0 \pm 15.5(21-96 / 57)$} & \multicolumn{2}{|c|}{$56.6 \pm 14.6(28-82 / 59)$} & 0.675 \\
\hline Additional Disease & 47 & 43.9 & 13 & 54.2 & 0.363 \\
\hline \multicolumn{6}{|l|}{ Fever } \\
\hline Normal & 79 & 72.5 & 17 & 68.0 & 0.654 \\
\hline High & 30 & 27.5 & 8 & 32.0 & \\
\hline Leukocyte (WBC) & \multicolumn{2}{|c|}{$12.6 \pm 4.9(5.4-29.8 / 12.2)$} & \multicolumn{2}{|c|}{$13.4 \pm 4.3(7.1-23 / 13.6)$} & 0.318 \\
\hline \multicolumn{6}{|l|}{ Mean \pm SD (Min-Maks/Median) } \\
\hline$\%$ NE Mean \pm SD (Min-Max/Median) & \multicolumn{2}{|c|}{$71.2 \pm 12.0(25.6-93.8 / 72.4)$} & \multicolumn{2}{|c|}{$72.6 \pm 13.4(36.3-93.9 / 72.2)$} & 0.605 \\
\hline CRP Mean $\pm S D$ (Min-Max/Median) & \multicolumn{2}{|c|}{$89.7 \pm 92.2(0.7-349.6 / 50.5)$} & \multicolumn{2}{|c|}{$87.0 \pm 79.5(1.2-288.4 / 74.4)$} & 0.864 \\
\hline \multicolumn{6}{|l|}{ Localization } \\
\hline Cecum & 19 & 17.6 & 0 & 0.0 & 0.023 \\
\hline Sigmoid & 67 & 62.0 & 17 & 68.0 & 0.578 \\
\hline Descending Colon & 23 & 21.3 & 3 & 12.0 & 0.405 \\
\hline Ascending Colon & 3 & 2.8 & 1 & 4.0 & 0.570 \\
\hline Transverse Colon & 7 & 6.5 & 1 & 4.0 & 1.000 \\
\hline Rectosigmoid Colon & 4 & 3.7 & 5 & 20.0 & 0.012 \\
\hline Entire Colon & 4 & 3.7 & 1 & 4.0 & 1.000 \\
\hline Meckel diverticulum & 2 & 1.9 & 0 & 0.0 & 1.000 \\
\hline 1 & 87 & 83.7 & 19 & 76.0 & 0.169 \\
\hline Hinchey Classification & 2 & 5 & 4.8 & 4 & 16.0 \\
\hline 3 & 7 & 6.7 & 2 & 8.0 & \\
\hline 4 & 5 & 4.8 & 0 & 0.0 & \\
\hline Medical & 94 & 86.2 & 18 & 72.0 & 0.001 \\
\hline Elective Surgery & 0 & 0.0 & 4 & 16.0 & \\
\hline \multicolumn{6}{|l|}{ Treatment } \\
\hline Emergency Surgery & 14 & 12.8 & 2 & 8.0 & \\
\hline Percutaneous Drainage & 1 & 0.9 & 1 & 4.0 & \\
\hline Length of Hospital Stay & \multicolumn{2}{|c|}{$4.28 \pm 3.41(0-17 / 4)$} & \multicolumn{2}{|c|}{$5.79 \pm 5.03(0-20 / 5)$} & 0.221 \\
\hline \multicolumn{6}{|l|}{ Mean \pm SD (Min-Max/Median) } \\
\hline Mortality & 1 & 0.9 & 0 & 0.0 & 1.000 \\
\hline
\end{tabular}




\section{Discussion}

Many modifiable and nonmodifiable risk factors for diverticular disease of the colon, such as age, sex, weight, diet and lifestyle, drug use, and genetic makeup, have been identified.

However, controversy still continues over which of these risk factors are more prevalent. ${ }^{[6-8]}$ The diversity of these etiological factors also plays a role in the development of symptoms and the prognosis of the disease and causes the symptoms to differ. ${ }^{[9]}$ For example, individuals with connective tissue abnormalities are more asymptomatic, while in patients with predisposing factors, it leads to a course with complications. ${ }^{[9,10]}$

Patients with diverticulitis typically present with the complaint of acute or subacute abdominal pain developing in the left lower quadrant. Other common signs and symptoms include nausea, high fever, changes in bowel habits, and increased white blood cell count and inflammatory markers. ${ }^{[11,12]}$

Table 2. Complications and patient characteristics

\begin{tabular}{|c|c|c|c|c|c|}
\hline & \multicolumn{4}{|c|}{ Complication } & \multirow[b]{3}{*}{$\mathbf{p}$} \\
\hline & \multicolumn{2}{|c|}{ Absent } & \multicolumn{2}{|c|}{ Present } & \\
\hline & $\mathbf{n}$ & $\%$ & $\mathbf{n}$ & $\%$ & \\
\hline \multicolumn{6}{|l|}{ Sex } \\
\hline Male & 50 & 45.0 & 14 & 60.9 & 0.167 \\
\hline Female & 61 & 55.0 & 9 & 39.1 & \\
\hline Age Mean \pm SD (Min-Max) & \multicolumn{2}{|c|}{$57.7 \pm 15.0(28-96 / 57)$} & \multicolumn{2}{|c|}{$58.0 \pm 17.0(21-83 / 57)$} & 0.925 \\
\hline Additional Disease & 52 & 46.8 & 8 & 40.0 & 0.572 \\
\hline \multicolumn{6}{|l|}{ Fever } \\
\hline Normal & 91 & 82.0 & 5 & 21.7 & $<0.001$ \\
\hline High & 20 & 18.0 & 18 & 78.3 & \\
\hline Leukocyte (WBC) & \multicolumn{2}{|c|}{$12.3 \pm 4.6(5.4-29.8 / 11.8)$} & \multicolumn{2}{|c|}{$15.1 \pm 5.1(7.7-29.7 / 14.2)$} & 0.010 \\
\hline \multicolumn{6}{|l|}{ Ort. \pm SD (Min- Max) } \\
\hline$\%$ NE Mean \pm SD (Min-Maks) & \multicolumn{2}{|c|}{$69.7 \pm 12.2(25.6-93.9 / 70.8)$} & \multicolumn{2}{|c|}{$79.8 \pm 9.1(60-92.5 / 80.5)$} & $<0.001$ \\
\hline CRP Mean \pm SD (Min-Maks) & \multicolumn{2}{|c|}{$71.0 \pm 77.0(0.7-315 / 40)$} & \multicolumn{2}{|c|}{$175.4 \pm 96.7(3.6-349.6 / 184)$} & $<0.001$ \\
\hline \multicolumn{6}{|l|}{ Localization } \\
\hline Cecum & 17 & 15.5 & 2 & 8.7 & 0.526 \\
\hline Sigmoid & 69 & 62.7 & 15 & 65.2 & 1.000 \\
\hline Descending Colon & 21 & 19.1 & 5 & 21.7 & 0.776 \\
\hline Ascending Colon & 4 & 3.6 & 0 & 0.0 & 1.000 \\
\hline Transverse Colon & 8 & 7.3 & 0 & 0.0 & 0.350 \\
\hline Rectosigmoid Colon & 6 & 5.5 & 3 & 13.0 & 0.187 \\
\hline Entire Colon & 5 & 4.5 & 0 & 0.0 & 0.587 \\
\hline Meckel diverticulum & 0 & 0.0 & 2 & 8.7 & 0.029 \\
\hline \multicolumn{6}{|l|}{ Hinchey Classification } \\
\hline 1 & 102 & 94.4 & 4 & 19.0 & $<0.001$ \\
\hline 2 & 3 & 2,8 & 6 & 28.6 & \\
\hline 3 & 3 & 2.8 & 6 & 28.6 & \\
\hline 4 & 0 & 0.0 & 5 & 23.8 & \\
\hline Medikal & 107 & 96.4 & 5 & 21.7 & $<0.001$ \\
\hline \multicolumn{6}{|l|}{ Treatment } \\
\hline Elektif Cerrahi & 2 & 1.8 & 2 & 8.7 & \\
\hline Acil Cerrahi & 2 & 1.8 & 14 & 60.9 & \\
\hline Perkütan Drenaj & 0 & 0.0 & 2 & 8.7 & \\
\hline Length of Hospital Stay & \multicolumn{2}{|c|}{$3.5 \pm 2.5(0-12 / 4)$} & \multicolumn{2}{|c|}{$9.9 \pm 4.5(4-20 / 9)$} & $<0.001$ \\
\hline \multicolumn{6}{|l|}{ Mean $\pm S D$ (Min-Max) } \\
\hline Recurrence & 17 & 15.3 & 8 & 34.8 & 0.040 \\
\hline Mortality & 0 & 0.0 & 1 & 4.5 & 0.165 \\
\hline
\end{tabular}


In our study, of the laboratory tests, increase in CRP $(89.2 \pm 89.6)$ and neutrophil- dominated leukocyte increase $(12.8 \pm 4.8)$ were at the forefront, while the rate of patients with fever was $28.4 \%$.

Imaging is required to differentiate complicated patients from uncomplicated patients with colonic diverticulitis and determine the need for antibiotics, percutaneous abscess drainage, and surgery. An abdominal CT scan should be performed to evaluate complications, especially in patients with severe symptoms, and in patients with immune deficiency or who do not respond to the initial treatment. ${ }^{[13]}$ All of the diagnoses of diverticulitis in our study were made with contrast abdominal CT scan.

Treatment approach in acute diverticulitis depends on complications (abscess, perforation), severity of the disease and presence of comorbid disease. Patients with uncomplicated diverticulitis, and who are stable, with no additional disease can sometimes be treated on outpatient basis and without antibiotics. We did not have any patient in our clinic whom we treated on outpatient basis. The reason for this was that these patients were mostly symptomatic or had low immunity due to additional diseases. In these patients with abscess, elective surgical resection is performed after IV antibiotic and percutaneous drainage treatment. In our study, no additional intervention was required because the abscess of two patients was not very large and the infection disappeared completely after treatment. In patients with perforation and peritonitis, IV antibiotics and emergency surgery should be performed.

Many diverticulitis classification systems have been developed to provide disease severity and treatment management in acute diverticulitis. Modified Hinchey classification, which is widely used based on CT findings, is one of them. ${ }^{[14]}$ According to this classification, patients with stage 0 and stage 1 diverticulitis have uncomplicated diverticulitis. Patients with stage II disease (distal abscess) require antibiotics and usually percutaneous drainage to be prepared for elective resection. Patients with stage III and IV disease (purulent and fecal peritonitis) require emergency surgical treatment. Hinchey-based classification systems do not take into account the symptoms of chronic diverticulitis, such as stenosis, fistula, and recurrence, and therefore only greatly assist in the management of acute patients. ${ }^{[14]}$

In our study, according to the Hinchey classification indicating the severity of diverticulitis, the complication and longer hospital stay rates increased as the stage increased. The mean length of hospital stay in our patients was significantly lower in Hinchey stage $1(p<0.001)$.
Hinchey stage 2-3-4 rates and emergency surgery rate of patients with complications were high. Fever rate and biochemical inflammation parameters were also high in these patients (Table 2).

When the recurrence rates in these patients are examined, the risk of recurrence after the first diverticulitis attack is approximately $20 \%$ in 10 years, and the risk of recurrence after the second attack is $55 \%$ in 10 years. ${ }^{[15]}$ In our study, the mean recurrence rate was $18.7 \%$ at approximately 46 months. Recurrence rate was related to localization and independent of other factors. When one of the factors, localization, which may play a role in the severity of the disease and recurrence are examined, is evaluated in terms of its results in our study, we found that rectosigmoid location is an important factor for recurrence. In a study on this subject, right-sided colonic diverticulitis was self-limiting and less recurrent. ${ }^{[16]}$

\section{Conclusion}

As a result, we found that the localization in the colon and the severity of the disease were effective on the prognosis of acute diverticulitis. We believe that localization and the severity of the disease should be taken into consideration when planning surgery in these patients.

\section{Disclosures}

Ethics Committee Approval: For our study, research permission was obtained from the local ethics committee on 11.02.2020, numbered 2675.

Peer-review: Externally peer-reviewed.

Conflict of Interest: None declared.

Authorship Contributions: Concept - M.K.D.; Design - M.K.D., M.M.; Supervision - C.K., M.K.D., M.M.; Materials - C.K.; Data collection \&/or processing - Z.G.D.; Analysis and/or interpretation - Z.G.D.; Literature search - M.F.C.; Writing - C.K., M.K.D.; Critical review - M.M., M.F.C.

\section{References}

1. Jun S, Stollman N. Epidemiology of diverticular disease. Best Pract Res Clin Gastroenterol 2002;16:529-42. [CrossRef]

2. Etzioni DA, Mack TM, Beart RW Jr, Kaiser AM. Diverticulitis in the United States: 1998-2005: changing patterns of disease and treatment. Ann Surg 2009;249:210-7. [CrossRef]

3. Tursi A. Acute diverticulitis of the colon-current medical therapeutic management. Expert Opin Pharmacother 2004;5:55-9.

4. Tursi A, Papa A, Danese S. Review article: the pathophysiology and medical management of diverticulosis and diverticular disease of the colon. Aliment Pharmacol Ther 2015;42:664-84. [CrossRef]

5. Hinchey EJ, Schaal PG, Richards GK. Treatment of perforated diverticular disease of the colon. Adv Surg 1978;12:85-109.

6. Strate LL, Morris AM. Epidemiology, Pathophysiology, and Treat- 
ment of Diverticulitis. Gastroenterology 2019;156:1282-98.e1.

7. Böhm SK, Kruis W. Lifestyle and other risk factors for diverticulitis. Minerva Gastroenterol Dietol 2017;63:110-8.

8. Jovani M, Ma W, Joshi AD, Liu PH, Nguyen LH, Cao Y, et al. Menopausal Hormone Therapy and Risk of Diverticulitis. Am J Gastroenterol 2019;114:315-21. [CrossRef]

9. Tursi A, Scarpignato C, Strate LL, Lanas A, Kruis W, Lahat A, et al. Colonic diverticular disease. Nat Rev Dis Primers 2020;6:20.

10. Wedel T, Barrenschee M, Lange C, Cossais F, Böttner M. Morphologic Basis for Developing Diverticular Disease, Diverticulitis, and Diverticular Bleeding. Viszeralmedizin 2015;31:76-82. [CrossRef]

11. Laurell H, Hansson LE, Gunnarsson U. Acute diverticulitis-clinical presentation and differential diagnostics. Colorectal Dis 2007;9:496-501. [CrossRef]

12. Nizri E, Spring S, Ben-Yehuda A, Khatib M, Klausner J, Greenberg R. C-reactive protein as a marker of complicated diverticulitis in patients on anti-inflammatory medications. Tech Coloproctol 2014;18:145-9. [CrossRef]

13. Feingold D, Steele SR, Lee S, Kaiser A, Boushey R, Buie WD, et al. Practice parameters for the treatment of sigmoid diverticulitis. Dis Colon Rectum 2014;57:284-94. [CrossRef]

14. Wasvary H, Turfah F, Kadro O, Beauregard W. Same hospitalization resection for acute diverticulitis. Am Surg 1999;65:632-5.

15. Bharucha AE, Parthasarathy G, Ditah I, Fletcher JG, Ewelukwa O, Pendlimari R, et al. Temporal Trends in the Incidence and Natural History of Diverticulitis: A Population-Based Study. Am J Gastroenterol 2015;110:1589-96. [CrossRef]

16. Yardımcı E, Hasbahçeci M, İdiz UO, Atay M, Akbulut $H$. Is surgery necessary to confirm diagnosis of right-sided diverticulitis in spite of relevant clinical and radiological findings? Ulus Travma Acil Cerrahi Derg 2017;23:61-5. 